\title{
Avaliação institucional da escola: conceitos, contextos e práticas
}

\section{School institutional assessment: concepts, contexts and practice}

\author{
Mary Ângela Teixeira Brandalise*
}

\begin{abstract}
Resumo: A relevância dos processos avaliativos para a concretização dos fins educacionais e da escola e o reconhecimento da interdependência dos múltiplos objetos de análise da avaliação educacional e dos seus níveis de estrutura - micro, meso, macro e megassociológicos - para a efetivação de um processo avaliativo na escola são os propósitos da investigação apresentada neste texto. A pesquisa de cunho qualitativo, exploratória/bibliográfica, teve como procedimento a análise documental de livros e publicações relacionados à avaliação educacional e à avaliação de instituições escolares, numa perspectiva sociológica, com ênfase na autoavaliação da escola. O artigo está estruturado em três partes: avaliação educacional na contemporaneidade, avaliação institucional da escola, e autoavaliação da escola e desenvolvimento institucional. Nelas são discutidos alguns aportes e subsídios teóricos sobre a avaliação institucional e as possibilidades de operacionalizá-la na escola.
\end{abstract}

Palavras-chave: Avaliação institucional. Autoavaliação de escolas. Desenvolvimento institucional.

\begin{abstract}
The relevance of assessment processes to meet educational goals and school aims as well as the acknowledgment of the interdependence of the multiple objects of analysis of educational assessment and of their micro, meso, macro and mega sociological structure levels to the implementation of the assessment process in schools are the purposes of the investigation discussed in this article. The qualitative exploratory/document research included a document analysis of books and publications related to educational assessment and school institutional assessment from a sociological perspective paying special attention to school self-assessment. The article is divided in three parts: contemporary educational assessment, school institutional assessment and, school self-assessment and institutional development. Some of the theoretical frameworks about institutional assessment and the possibilities of its implementation in schools are discussed.
\end{abstract}

Keywords: Institutional assessment. School Self-assessment. Institutional development.

\section{Introdução}

As razões de ordem socioeconômica, político-administrativa, científico-pedagógica e legal que justificam a necessidade de a escola se autoavaliar são abordadas neste ensaio teórico a fim de explicitar a importância da avaliação institucional das escolas e também trazer elementos conceituais que contribuam, por um lado, para a compreensão da avaliação educacional e da avaliação da escola para captar o movimento institucional; e, por outro lado, para propiciar um refinamento metodológico no campo da avaliação de escolas, compreendendo que a avaliação, se entendida como uma análise crítica da

\footnotetext{
* Doutora em Educação: Currículo pela PUC/SP e professora do Programa de Pós-graduação em Educação da UEPG. Email: marybrandalise@uol.com.br
} 
realidade, é fonte valiosa de informação, problematização e ressignificação dos processos educativos, tendo, consequentemente, função estratégica no desenvolvimento institucional da escola e na gestão educacional.

Com o ensaio teórico aqui apresentado pretende-se não apenas socializar parte da produção da pesquisa já realizada, mas também apresentar aos leitores e pesquisadores, em educação e avaliação, alguns contributos teórico-metodológicos de referência para a realização de estudos, pesquisas e projetos relativos à avaliação de escolas e ao desenvolvimento institucional por meio de uma exposição lógica e reflexiva, e uma argumentação rigorosa oriunda de pesquisas sobre avaliação de escolas e práticas em gestão e avaliação educacional

O artigo está estruturado em três partes. Na primeira parte, busca-se na pesquisa e na produção teórica sobre avaliação educacional novas concepções e compreensões sobre os processos avaliativos na contemporaneidade. Na segunda, discute-se alguns aportes e subsídios teóricos sobre a avaliação institucional da escola, trazendo-se à reflexão os conceitos de avaliação, seus fundamentos epistemológicos, suas relações com diferentes contextos e as possibilidades de operacionalização do processo de autoavaliação da escola, considerando-se desde a fase do planejamento até a fase de comunicação dos resultados obtidos. Na terceira, trata-se da utilização dos resultados na elaboração do plano de ação da escola, ou seja, da utilidade da autoavaliação institucional.

\section{Avaliaçao educacional na contemporaneidade}

A palavra avaliação contém a palavra “valor” acrescida da palavra “ação”; portanto, não se pode fugir dessa concepção valorativa da ação educacional. Casali (2007, p.10) define avaliação, "de modo geral, como saber situar cotidianamente, numa certa ordem hierárquica, o valor de algo enquanto meio (mediação) para a realização da vida do(s) sujeitos(s) em questão, no contexto dos valores culturais e, no limite, dos valores universais."

Para o autor avaliar é reconhecer ou atribuir um valor. Em se tratando de valor em educação, ele defende que há que se adotar uma postura radicalmente ética e epistemológica. Os valores são histórica e culturalmente construídos, consequentemente a avaliação é histórica e cultural. Já que o valor só existe como referência mediadora de uma ação concreta, a decorrência disso é que a avaliação educativa não é um fim de processo, mas o seu meio. Existem três âmbitos de alcance dos valores, logo, das avaliações: “Há valores para um sujeito, há valores para uma cultura, há valores para a humanidade. O singular, o parcial, o universal. A avaliação é uma medida e uma referência de valor para um, ou dois, ou os três âmbitos." (CASALI, 2007, p. 13).

$\mathrm{O}$ autor explica que a avaliação refere-se à determinação do mérito ou valor de um dado processo ou do que dele resultou, seja no âmbito do sujeito, da cultura, ou de toda humanidade.

A complexidade inerente aos processos avaliativos torna evidente a exigência com os resultados do desempenho dos alunos e com o desempenho das escolas, mostra que atualmente a avaliação educacional tem uma perspectiva muito mais ampliada, não se atendo apenas aos resultados do rendimento escolar, mas a todos os elementos que permeiam o processo ensino-aprendizagem, ou seja, a toda a realidade educativa.

Figari (1996) afirma que, nessa acepção mais alargada de avaliação educacional, há a noção de estrutura que define realidades 
diferentes: as macroestruturas (os sistemas educacionais), as mesoestruturas (as escolas) e as microestruturas (as salas de aulas). No espaço da macro e da mesoestrutura, a avaliação geralmente é o processo de observação e interpretação dos resultados da aprendizagem que objetiva orientar as decisões necessárias ao bom funcionamento da escola, dos sistemas educacionais e subsidiar a formulação de políticas públicas.

Na mesma linha de raciocínio, Almerindo Afonso (2003) analisa a avaliação educacional numa perspectiva sociológica, nos seguintes níveis: micro, meso, macro e mega. A perspectiva de avaliação defendida pelo autor entende que a "escola é confrontada com dimensões éticas, simbólicas, políticas, sociais e pedagógicas que devem ser consideradas como um todo por quem tem especiais responsabilidades na administração da educação quer em nível do Estado, quer em nível municipal e local, quer em nível da própria unidade escolar”. (AFONSO, 2003, p. 49).

O nível microssociológico da avaliação ocorre no âmbito da sala de aula, é a avaliação da aprendizagem, de responsabilidade do docente. Ela deve ter caráter fortemente formativo, ser contínua e baseada na reflexão do processo ensino-aprendizagem.

O nível mesossociológico da avaliação é aquele que envolve a análise de uma instituição escolar na sua totalidade, ou seja, engloba todos os componentes do processo educacional: gestão e organização da escola, processo ensino-aprendizagem, currículo, qualificação docente, infraestrutura escolar, resultados educacionais, perfil socioeconômico dos alunos, ação da escola com a sociedade, participação dos pais, entre outros aspectos da escola.

O nível macrossociológico da avaliação é aquele desenvolvido em âmbito nacional, por organismos externos à escola, e tem como objetivo verificar a qualidade do ensino e da educação no país. No Brasil há o INEP - Instituto Nacional de Estudos e Pesquisas Educacionais, que coordena os processos de avaliação externa às escolas. São exemplos desse tipo de avaliação a Prova Brasil, o SAEB - Sistema de Avaliação da Educação Básica, o ENEM - Exame Nacional do Ensino Médio.

O nível megassociológico da avaliação é aquele desenvolvido por organismos internacionais que buscam fixar padrões de desempenho, de referência para a criação de metas e diretrizes para os sistemas educacionais de diferentes países, em nível global. Tem-se como exemplo o PISA - Programa Internacional de Avaliação de Alunos, coordenado pela Organização de Cooperação e Desenvolvimento Econômico - OCDE.

A criação desses níveis mais globais (mega e macro) deve-se ao fato de a avaliação ter adquirido grande centralidade nas políticas públicas pelos organismos governamentais, particularmente nas políticas educacionais, com o propósito de os Estados ampliarem as ações de controle e fiscalização sobre as escolas e os sistemas educacionais, fenômeno apontado pelos estudiosos em avaliação como a presença do "Estado Avaliador” na educação.

\section{Avaliação institucional da escola}

A avaliação institucional da escola básica ainda não se constitui uma prática consolidada no contexto da educação brasileira. A avaliação externa promovida pelos organismos oficiais como o SAEB, e com as recentes propostas da Prova Brasil e do IDEB, é uma avaliação do sistema educacional, em larga escala, que analisa a proficiência dos estudantes ao final de um ciclo da escolaridade. No entanto, a avaliação interna é pouco 
realizada no interior das escolas, não está inserida nas várias ações nelas desenvolvidas, como uma análise sistemática da instituição com vistas a identificar suas fragilidades e potencialidades e a possibilitar a elaboração de planos de intervenção e melhorias. Estudos e pesquisas revelam a carência de formação dos profissionais da escola para desenvolvê-la, devido ao desconhecimento de fundamentos teórico-metodológicos sobre a avaliação institucional.

Com o propósito de contribuir para a formação dos profissionais da escolas e também para a operacionalização do processo de autoavaliação, discute-se aqui alguns fundamentos teórico-metodológicos sobre a avaliação institucional da escola, suas relações com diferentes contextos e as possibilidades de operacionalização de processo de auto-avaliação da escola.

\section{Avaliação da escola: conceitos, contextos e relações}

A avaliação das instituições escolares e a de outros objetos educacionais avaliados podem (ou não) assentar-se nos mesmos fundamentos teóricos. Assim, quando se fala na concepção de avaliação adotada num processo avaliativo, ele pode ser atribuído tanto à avaliação da aprendizagem, de currículo, de docentes, de políticas públicas, de programas, de projetos quanto à avaliação das instituições escolares específicas, como as escolas básicas, os institutos de ensino superior, as universidades, entre outras.

Toda instituição, sobretudo a educacional, apresenta características orgânicas que justificam essa correspondência e, consequentemente, o similar fundamento para os processos de avaliação. Uma instituição escolar é compreendida como um conjunto de processos e relações que se produzem em seu cotidiano pelos sujeitos nela inseridos: educadores e educandos, essencialmente.

A avaliação institucional numa perspectiva crítica é aquela que consegue captar o movimento institucional presente nas relações da instituição. Toda instituição é constituída por dois princípios em permanente tensão: o instituído e o instituinte. Castoriades (1975) explica que o instituído é o conjunto de forças sedimentadas, consolidadas, que buscam a conservação e reprodução do quadro institucional vigente. $\mathrm{O}$ instituído é a forma. Já o conjunto de forças em constante estado de tensão, de mudança, de transformação, de recriação é o instituinte. $\mathrm{O}$ instituinte é o campo de forças.

A avaliação institucional é formalmente a avaliação desse instituído e instituinte. Ela tem que identificar aspectos concretos, formais e informais, explícitos ou não, internos e externos, que viabilizam a realização dos objetivos e fins educacionais propostos num projeto institucional. Há, portanto, que se considerar toda a dinâmica institucional para captar o espírito da instituição avaliada. Nesta perspectiva, a avaliação institucional tem um caráter formativo, está voltada para a compreensão e promoção da autoconsciência da instituição escolar.

Nos debates contemporâneos sobre a educação há uma exigência cada vez maior com o desempenho da escola, porque ela é considerada uma instituição social imprescindível à sociedade atual, à formação humana, ainda que essa exigência se exprima de modos variados e contraditórios.

Após um período de oscilação das questões avaliativas entre o nível macro do sistema educacional e o nível micro da sala de aula, é justamente para o contexto da instituição escolar - nível meso - que as propostas de inovações educacionais, segundo 
Nóvoa (1995), têm se voltado, acreditandose que é no espaço escolar que elas podem implantar-se e desenvolver-se.

No entanto, uma das abordagens da avaliação institucional das escolas que se apresenta compreende aquela que tem como eixo direcionador a ação ordenada de normas e prerrogativas da União, isto é, o Estado se transforma num avaliador externo, conforme já apontado anteriormente. Denominado de Estado Avaliador, ele tem o papel de controlar, monitorar, credenciar e oferecer indicadores de desempenho para as escolas e os sistemas de ensino dos países. Normalmente decidida por razões de ordem macroestrutural que se prendem às necessidades de controle organizacional no nível dos sistemas de ensino, essa modalidade é chamada de avaliação institucional externa.

A avaliação externa é, portanto, aquela em que o processo avaliativo é realizado por agentes externos à escola (pertencentes a agências públicas ou privadas), ainda que com a colaboração indispensável dos membros da escola avaliada, da comunidade educativa.

Outra abordagem é aquela denominada de autoavaliação institucional ou avaliação interna da escola. Diferentemente da avaliação externa, ela é uma modalidade de avaliação que ainda carece de maior aprofundamento teórico e metodológico, particularmente no contexto brasileiro.

A avaliação institucional da escola é produto da integração e entrelaçamento dos processos de avaliação externa e interna. É evidente que a avaliação das escolas é uma tarefa complexa, tendencialmente conflituosa, pois as instituições escolares são organizações, e o poder é inerente a todas as organizações. Ao "mexer” nesse poder, num processo de avaliação da escola, interfere-se nos interesses, posturas, motivações e objetivos da comunidade escolar. $\mathrm{O}$ processo de avaliação externa deverá completar-se com o processo de autoavaliação institucional, e vice-versa. É a coavaliação, como propõe Santos Guerra (2003), isto é, a combinação do processo de avaliação externa, mais voltado aos resultados do processo educativo, e avaliação interna, centrada na melhoria dos processos internos do trabalho escolar.

Cabe aqui chamar atenção para os problemas que podem surgir na escola conforme a natureza que lhe dá origem, associada com o tipo de avaliação escolhida:

$1^{\text {a) }}$ avaliação externa de iniciativa externa (organismos oficiais);

$2^{a}$ ) avaliação externa de iniciativa interna (da própria escola);

$3^{\text {a) }}$ avaliação interna de iniciativa interna.

$\mathrm{Na}$ primeira, avaliação externa de iniciativa externa, geralmente há uma interpretação dos avaliados de que está se desencadeando um processo de fiscalização e controle do trabalho escolar, com objetivo de estabelecer medidas comparativas, rankings, ou ainda, com uma característica de punição ou premiação, para piores e melhores desempenhos. O que pode acontecer num processo de avaliação externa da escola é a geração de mecanismos internos de defesa, buscando dar aos avaliadores uma imagem distorcida da realidade escolar.

Na avaliação externa de iniciativa interna, a escola pode escolher um avaliador para atender seus interesses, que esteja de acordo com a filosofia adotada pela escola, e as informações podem ser ocultadas se os resultados forem contrários aos anseios e intenções da comunidade escolar.

Quanto à avaliação interna, proposta pela própria instituição escolar, é preciso estar atento a diversos problemas que podem surgir: a hostilidade e resistência em relação 
ao processo avaliativo, a credibilidade ética profissional do avaliador, o caráter individualista da função docente, a falta de apoio técnico, logístico e de tempo, a impaciência pela obtenção dos resultados, a ocultação de informações fundamentais, a falta de motivação profissional, a imersão da equipe avaliadora na realidade avaliada, as pressões internas por interesses, a inércia institucional, ou seja, a própria cultura da escola.

Aliado aos aspectos apontados, outro que consideramos de muita relevância é a formação da equipe responsável pelo processo avaliativo, pois poucos profissionais dedicam-se ao campo da avaliação de escolas como objeto de estudo.

Nesse contexto, o desconhecimento dos fundamentos teóricos da avaliação institucional, especificamente das escolas da Educação Básica, pode gerar a falta de planejamento, objetividade e credibilidade perante a comunidade escolar. Deve-se ter uma competência científica e técnico metodológica que direcione o desenvolvimento da avaliação interna da escola, proporcionando-lhe assim legitimidade.

As escolas são cada vez mais caracterizadas como centros de aprendizagem de todos os seus membros e da sua própria organização. Enquanto organizações nucleares das sociedades atuais, elas não podem ficar indiferentes às mudanças e transformações que nelas acontecem, sejam de natureza econômica, política, científica, pedagógica ou legal. Para tanto, não se deve proceder à sua apreciação através de uma análise individualizada de cada um dos seus elementos, mas sim apreendê-la como um todo, como uma entidade global, original. Segundo Rocha (1999), a necessidade de avaliá-las é devida a um conjunto de razões: a) Razões de ordem socioeconômica:

- A contenção de recursos financeiros para os gastos públicos, considerando-se as recentes e repetidas crises econômicas.

- A democratização da sociedade e o desenvolvimento dos processos de participação social, particularmente no campo educacional.

- A pressão da opinião pública geralmente apoiada numa avaliação "selvagem" baseada em boatos, na comparação entre escolas, ou seja, em ranqueamentos, ou ainda, na exposição pública de resultados e fragilidades do sistema educacional pela mídia, muitas vezes não condizente com a realidade das escolas e com as concepções dos programas e projetos de avaliação adotados.

b) Razões de ordem político-administrativa:

- A sociedade tornou-se mais exigente quanto ao desempenho das escolas e a sua função de diminuir as desigualdades sociais. Os poderes públicos passam a investir mais na educação e, consequentemente, a solicitar às escolas que justifiquem tais gastos e suas aplicações.

- O aumento da autonomia das escolas a partir dos anos 90 (noventa) com a democratização da sociedade e a descentralização administrativa, em virtude da ineficiência do Estado em gerir com eficácia o sistema educacional.

- A legitimidade de os governos democráticos controlarem, no âmbito das suas competências, o desempenho das escolas, questionando-as sobre a eficiência, eficácia, efetividade e relevância da sua ação educativa, particularmente a das escolas públicas. 
- À medida que a sociedade se complexifica, as mudanças sociais são mais rápidas e imprevisíveis e os sistemas educacionais são maiores, a escolaorganização vai se tornando o meio natural e mais importante de muitos projetos de mudança educacional.

c) Razões de ordem científico-pedagógica:

- Novas abordagens sobre os problemas das escolas e da educação, introduzidas pela comunidade científica a partir de suas investigações: a valorização dos contextos escolares, a busca pelos fatores explicativos da diferença de qualidade entre as escolas, a passagem de uma pedagogia centrada no aluno para outra centrada na escola, e a problematização da eficácia das reformas educacionais, tanto em nível local como global.

- A consideração progressiva da avaliação da escola como estratégia de inovação para introdução dos próprios processos de mudanças nos espaços escolares.

- A evolução das concepções de avaliação da educação, que, de uma visão voltada quase que exclusivamente para os alunos e programas, passaram a valorizar os fatores relacionados não somente ao contexto de sala de aula, mas também os fatores que permitem uma ação mais ajustada aos demais contextos e objetivos educacionais, na busca da melhoria da qualidade dos processos educativos (práticas) e dos seus resultados (produtos). d) Razões de ordem legal:

- As mudanças na legislação nacional a partir da Lei de Diretrizes e Bases da Educação Nacional - LDBEN 9394/96, que aponta para a autonomia das escolas e consequente abertura para a necessidade da sua avaliação. Faz referência à Organização da Educação Nacional, no artigo $9^{\circ}$., incisos V, VI e VIII, ressaltando o princípio da avaliação como uma das partes centrais da estrutura administrativa da educação.

As razões apresentadas justificam a necessidade da existência da avaliação das escolas. É uma nova exigência com a qual as escolas são confrontadas, e precisam aprender a fazer.

\section{Autoavaliação da escola: alinhavando sentidos, produzindo significados}

A problematização em torno da avaliação da escola tem evidenciado a necessidade de discutir, por um lado, a importância da avaliação institucional como processo que permeia o trabalho educativo e o aprimoramento do processo de gestão escolar; por outro, a possibilidade de institucionalização de práticas avaliativas assentadas numa política de mudança e desenvolvimento da qualidade educativa, levando-se em conta a singularidade de cada escola, e não somente a obrigação de resultados pré-estabelecidos e estandardizados pelos organismos oficiais, como na avaliação externa.

A autoavaliação da escola é aquela em que o processo é conduzido e realizado por membros da comunidade educativa. Pode ser definida como uma análise sistemática da escola com vistas a identificar os seus 
pontos fortes e fracos e a possibilitar a elaboração de planos de intervenção e melhorias. Frequentemente é realizada tendo como motivação principal o acompanhamento do projeto pedagógico da escola, no quadro de uma dinâmica de desenvolvimento organizacional e institucional. A avaliação inserida nas várias ações desenvolvidas na escola se coloca como mediadora do crescimento da comunidade escolar, portanto:

O projeto pedagógico e a avaliação institucional estão intimamente relacionados. A não existência de um desses processos ou a separação deles trará danos para a própria escola, Sem um projeto pedagógico que delimite a intencionalidade da ação educativa e ofereça horizontes para que a escola possa projetar seu futuro, faltará sempre à referência de todo o trabalho e suas concepções básicas. (FERNANDES, 2002, p.58).

Porque a avaliação institucional interna das escolas não é tão facilmente operacionalizável como se acredita ou propõe ser, não é fácil construir formas de autoavaliação que consigam lidar com os efeitos e tensões que são decorrentes da pluralidade de sentidos, poderes, dilemas e perspectivas que se estabelecem/interagem num contexto escolar.

A avaliação institucional interna ou autoavaliação constitui-se num processo de busca da realidade escolar, com suas tendências, seus saberes, seus conflitos e dilemas.

Deve dar suporte às decisões e mudanças na prática educativa. É dinâmica, por isso tem que ganhar lugar como processo que perpassa a ação escolar e o desenvolvimento curricular, explicitando assim os propósitos da escola e suas relações com a sociedade.

A avaliação institucional centrada na escola tem as seguintes características:
- é o processo pelo qual a escola é capaz de olhar criticamente para si mesma com a finalidade de melhorar o seu desempenho, através da identificação de áreas mais problemáticas e da procura de soluções mais adequadas, para o desenvolvimento do trabalho escolar;

- é uma investigação permanente do sentido da organização e das ações da escola conduzida pelos próprios profissionais do estabelecimento de ensino;

- é o processo de melhoria da escola, conduzido através quer da construção de referenciais, quer da procura de fatos comprobatórios, evidências, para formulação de juízo de valor;

- é um exercício coletivo, assentado no diálogo e no confronto de perspectivas sobre o sentido da escola e da organização;

- é um processo de desenvolvimento profissional;

- é um ato de responsabilidade social;

- é uma avaliação orientada para a utilização;

- é um processo conduzido internamente, mas que pode e deve contar com a assessoria de agentes externos.

\section{Abordagens teórico-metodológicas da autoavaliação da escola}

\section{Abordagem racionalista ou naturalista?}

Para a realização de qualquer processo de avaliação de escolas é fundamental a escolha e aceitação de uma concepção de análise. Tradicionalmente duas abordagens epistemológicas de avaliação se destacaram: a concepção racionalista de origem positivista, também denominada de quantitativa, e a 
concepção naturalista de origem construtivista, também chamada de qualitativa. Tais perspectivas teóricas também são válidas para a avaliação das escolas, pois irão definir a estrutura científica, a visão de mundo, a filosofia através da qual se fará a leitura da realidade social que se quer avaliar.

Ao optar-se pela abordagem quantitativa considera-se a educação como um processo tecnológico, acredita-se na objetividade da avaliação e utiliza-se o método hipotético-dedutivo. Os resultados são mais valorizados que os processos da educação, a finalidade da avaliação é o controle e se atribui mais valor ao caráter estável do que ao caráter dinâmico da realidade educacional. A abordagem qualitativa, ao contrário, considera a educação sempre ligada a valores, problematiza a objetividade da avaliação utilizando métodos mais qualitativos e compreensivos, valoriza os processos mais que os resultados da educação, considerando como finalidade principal da avaliação a melhoria. Além disso, valoriza mais o caráter dinâmico e subjetivo da realidade educacional.

As duas perspectivas avaliativas têm suas fragilidades. A racionalista ou quantitativa procura traduzir a realidade escolar em números, medidas e corre o risco de deformá-la, parecendo que a exprime fielmente. Isso ocorre porque, por um lado, desvaloriza a importância dos contextos, fontes ricas de significação; e, por outro, a simplifica, reduzindo a sua multidimensionalidade qualitativa a uma unidimensionalidade quantitativa. A abordagem naturalista, crítica ou qualitativa, ainda que atualmente seja considerada a melhor para o estudo dos fenômenos educacionais, pode intensificar algum subjetivismo intencional e gerar interpretações distorcidas da realidade educativa.

Atualmente estudiosos (BONNIOL, 2001; FERNANDES, 2002) apontam que as abordagens quantitativa e qualitativa devem ser entendidas como complementares e serem usadas em função das necessidades do processo avaliativo. Eles argumentam que, embora essa prática possa exigir mais tempo, formação e recursos, o esforço vale a pena para "realizar triangulações necessárias ao suporte das conclusões, para se conseguir um fortalecimento mútuo de métodos e para atender a pluralidade e diversidade das iniciativas, dos tipos, das finalidades, dos enfoques e dos objetos de avaliação”. (ROCHA, 1999, p. 49).

\section{Operacionalização do processo de autoa- valiação da escola}

Cada escola pode estabelecer as etapas para a construção do processo interno de avaliação. Para defini-lo algumas escolhas de fundo são necessárias, tais como: - O que avaliar; quais dimensões? (objetos de análise ou de avaliação da escola); - Quem pode/ deve avaliar a escola? (sujeitos, grupo de trabalho); - Com que finalidades? (objetivos); Com quais enfoques? (concepções e tipos de avaliação: interna /externa); - Como, quando, onde, com quem, com quais recursos? (metodologia, fontes; instrumentos; coleta, organização e análise dos dados; cronograma); - Como divulgar os resultados e propor melhorias? (planos de intervenção).

Para que essas escolhas venham a consubstanciar-se num plano é essencial relacioná-las entre si e articulá-las com a finalidade e o foco da avaliação, isto é, estabelecer a operacionalização do processo avaliativo.

Fernandes (2002) propõe três etapas, que aqui apresentamos a título de sugestão: preparação, implementação e síntese. 
$1^{\text {a) }}$ Etapa de Preparação - compreende as ações que antecedem a implementação do processo avaliativo.

- constituição da equipe de trabalho da escola;

- elaboração de uma proposta de avaliação preliminar para a escola;

- discussão da proposta com a comunidade escolar.

- definição do projeto de autoavaliação contendo os seguintes elementos: justificativa, referencial teórico, objetivos, dimensões a serem avaliadas (objetos de avaliação), procedimentos metodológicos, cronograma, recursos, referências.

$\left(2^{a}\right)$ Etapa de Implementação - compreende as ações de elaboração e aplicação de instrumentos de coleta de dados, organização e análise dessas informações.

- elaboração, discussão, testagem e aplicação dos instrumentos de coleta de informações;

- apuração e organização dos dados coletados;

- discussão coletiva dos dados coletados com a comunidade escolar.

(3 $3^{a}$ Etapa de Síntese - compreende as informações já organizadas, que deverão servir de orientação para ações que a escola desenvolverá a partir da análise dos resultados pela comunidade escolar.

- revisão e ajustes no processo avaliativo;

- elaboração de relatórios conclusivos;

- discussão sobre o uso dos resultados, com encaminhamento de ação;

- publicação e divulgação do relatório final.

Para se autoavaliar, a escola precisa construir um referencial de análise que considere a sua identidade institucional, seus sujeitos e as finalidades da avaliação. O primeiro passo é a definição de dimensões, categorias de análise ou subdimensões, e aspectos (indicadores) a serem avaliados. Existe uma hierarquia entre essas palavras, partindo-se de dados mais gerais para dados mais específicos:

- Dimensões: são os pontos de abrangência que deverão ser avaliados, as grandes áreas da avaliação. Elas podem abranger aspectos administrativos, pedagógicos, físicos e estruturais, relacionais.

- Categorias de análise ou subdimensões: são os pontos básicos dentro da dimensão escolhida que se pretende avaliar.

- Aspectos ou indicadores: são pequenos pontos indicadores para as perguntas em cada uma das categorias de análise.

Embora existam diferentes maneiras de se construir um referencial de análise para a realização da autoavaliação da escola, apresenta-se neste texto o referencial proposto por Alaiz, Góis, Gonçalves (2003), o qual indica seis áreas ou dimensões:

a) Dimensão I - Contexto externo: as variáveis de contexto externo não são maleáveis, ou seja, não são diretamente influenciadas pela ação da escola, mas esta é uma das áreas de avaliação de extrema importância, na medida em que permite enquadrar socialmente a escola. Ela pode ser composta pelas seguintes categorias de análise: caracterização social, econômica e cultural das famílias e alunos; expectativas das famílias e da comunidade quanto ao trabalho da escola; pressão para a qualidade na perspectiva do contexto externo, exercida por 
entidades ou grupos externos à escola: secretarias, núcleos regionais, associações de pais, ou outras instituições.

b) Dimensão II - Contexto interno: corresponde, numa linguagem simples, "às condições com que a escola conta”: história da instituição escolar; recursos físicos, estrutura curricular; corpo docente, administrativo e discente.

c) Dimensão III - Organização e gestão: as categorias de análise que compõem a área de organização e gestão dizem respeito à proposta pedagógica da escola e à sua execução e avaliação.

d) Dimensão IV - Ensino e aprendizagem: as categorias de análise de avaliação contempladas na área de ensino e aprendizagem convergem no trabalho realizado na sala de aula.

e) Dimensão V - Cultura da escola: as categorias associadas à cultura da escola podem ser: identidade institucional; ênfase no ensino e na aprendizagem; participação nos processos de decisão, motivação dos professores, expectativas acerca dos alunos, trabalho em equipe, aprendizagem e desenvolvimento profissional, reconhecimento dos profissionais da escola; disciplina e segurança na escola, aprazibilidade do espaço escolar, relação com a comunidade escolar.

f) Dimensão VI - Resultados Educacionais: os resultados dos alunos são as medidas de desempenho da escola. Em última análise, eles refletem a qualidade dos resultados intermediários contemplados nas restantes áreas. Ela pode ser composta pelas seguintes categorias de análise: qualidade do sucesso (classificações internas, estatísticas de resultados, provas estandardizadas, outros resultados não acadêmicos) e cumprimento da escolaridade

A escola pode ser avaliada considerando-se as seis dimensões apresentadas, ou pode escolher aquelas consideradas mais necessárias. No entanto, fundamental é que se parta de uma avaliação diagnóstica de todas as dimensões e que, a partir dos resultados alcançados, novas etapas avaliativas sejam desenvolvidas no interior da escola.

\section{Instrumentos: elaboração e aplicação}

Após a definição das dimensões, categorias de análise e indicadores, vem à etapa da escolha dos instrumentos e técnicas a serem utilizados no processo de autoavaliação para coleta dos dados - questionários, entrevistas, grupo focal, observação, portfólio, seminários, pesquisa em arquivos, análise de documentos, análise quantitativa, relatórios, dentre outros - os quais podem ser aplicados em grupos ou individualmente.

Os instrumentos escolhidos devem estar adequados às dimensões, categorias e indicadores propostos no projeto. É importante considerar que nenhum instrumento de avaliação é completo por si só, razão pela qual podem ser escolhidos tipos que se complementam.

Definidos os procedimentos, devem ser escolhidas as fontes de informação para coleta dos dados, as quais podem ser: documentos, projetos, planos, regimento escolar, gestores, professores, alunos, pais, funcionários, membros colegiados, membros da comunidade externa, dentre outros.

A etapa de aplicação dos instrumentos para coleta das informações constitui a fase mais difícil da pesquisa, que é passar pelo confronto com os sujeitos da avaliação, ou 
seja, com o seu público-alvo. É a fase de implantação do projeto, de provação, confronto com a realidade, de constatação de imperfeições, de ajustes que garantam a sua validade.

Se este fosse o processo de uma relação amorosa, dir-se-ia que passadas a fase do romance, em que domina o encantamento e o entusiasmo - A avaliação é a melhor forma de conhecer a escola e tem tudo para ser útil; nunca foi feito nada assim na escola - e a fase da crise, em que se descobre que nem tudo é perfeito e fácil - Para avaliar é necessário dominar as técnicas, escolher bem os instrumentos, ultrapassar dificuldades e gerir conflitos. (ALAIZ, GÓIS, GONÇALVES, 2003, p. 97)

Os autores complementam que é o momento de perceber se há motivação e disposição dos participantes para contribuir com as suas percepções sobre os aspectos solicitados na avaliação da escola. A coleta de dados precisa ser feita de uma forma não incomodativa, com discrição, com profissionalismo, pois a escola não para porque nela está em desenvolvimento um processo de autoavaliação. Portanto, discussões em grupo, entrevistas, aplicação de questionários, observações, devem ser realizados nos momentos que representem a menor alteração do cotidiano dos seus respondentes, pois ninguém deve deixar de realizar o seu trabalho habitual por causa da avaliação da escola.

\section{Tratamento, análise e interpretação dos dados}

Dependendo da natureza da informação coletada e das questões de avaliação, é possível optar-se por um processo de análise específico. Os dados de natureza quantitativa deverão ser objeto de análise estatística, e os de natureza qualitativa poderão ser apresentados em descrições, mas também poderão ser sujeitos a uma análise de conteúdo. Antes de se dar início ao tratamento das informações, procedeu-se a uma verificação dos dados brutos para prepará-los para a primeira análise, o que comumente se designa "limpeza" dos dados.

Em seguida realizou-se a análise propriamente dita, integrando e sintetizando os resultados. O trabalho de análise de dados consiste em reduzi-los ou condensá-los em tabelas, gráficos, sumários estruturados em função de categorias de análise, sinopses, registros de pequenos episódios, diagramas que mostram a relação entre eles. São apresentações das informações coletadas nos instrumentos de modo sintetizado, que permitem uma primeira análise para a qual é importante ter presentes os objetivos e as questões de avaliação inicialmente propostas. Dela emergem as primeiras tendências, as primeiras imagens da escola, ainda não articuladas numa imagem global: são os resultados preliminares. Eles geralmente suscitam mais perguntas, ora porque se encontram discrepâncias, ora porque existe uma combinação de informações não prevista ou pensada, que implica um novo olhar aos dados originais.

Concluída essa etapa, os resultados devem ser organizados de acordo com as dimensões, categorias e indicadores propostos no projeto de autoavaliação. Assim, serão reveladas as imagens da escola.

A obtenção deste retrato é um momento de celebração no desenvolvimento do processo avaliativo. Por um lado, porque se chegou a esse retrato da escola, por outro, porque estes resultados são a matéria-prima para o momento mais difícil do processo, o da interpretação e consequente elaboração de conclusões e reco-mendações; o momento de extrair da autoavaliação a sua utilidade, mas também o momento de todos os conflitos. (ALAIZ, GÓIS, GONÇALVES, 2003, p. 102). 
Os significados desses resultados expressam o pensamento do coletivo escolar que participou do processo avaliativo. Os dados não falam por si só, por isso há necessidade de interpretá-los, ou seja, estabelecer em que medida os resultados são positivos ou negativos, significam sucessos ou fracassos, pontos fortes ou pontos frágeis, mostrando assim as potencialidades e fragilidades da escola, e as áreas em que a escola precisa melhorar.

A divulgação dos resultados à comunidade escolar é fundamental para legitimação do processo avaliativo. Eles devem ser apresentados, divulgados e debatidos de forma alargada, oportunizando a manifestação de pontos de vista e a revisão de conclusões, quando as discussões acrescentarem contribuições que auxiliem no aprofundamento da interpretação. Um relatório deve responder necessariamente a três questões: Quais são os resultados da avaliação? Como se chegou a esses resultados? Face a esses resultados, o que se pode fazer para melhorar? Portanto, um relatório de autoavaliação da escola constitui-se não só num documento em que a escola fala de si, mas também num instrumento de trabalho para subsidiar a análise do que se pode fazer para melhorar.

Ainda que a opção teórico-metodológica do processo avaliativo deva ser escolhida pela escola, há que se iniciar o trabalho com um planejamento de preparação do projeto coletivo, seguido de sua implementação e síntese dos resultados obtidos. É um ciclo avaliativo que envolve diferentes momentos possibilitadores de se construir um retrato da escola para analisá-la com base em evidências válidas e fiáveis, retirando da autoavaliação aquilo que dá sentido à vida da escola, bem como a sua utilidade para a criação de propostas de melhorias internas voltados ao desenvolvimento institucional.

\section{Autoavaliação da escola e desenvolvimento institucional}

A autoavaliação da escola é um processo necessário para compreender a dinâmica institucional, que pode e deve ser útil para a escola, desde que não se traduza apenas na identificação de pontos fortes e de fragilidades, mas, também, na elaboração de recomendações que deverão ser consideradas na proposição de melhorias qualitativas para a instituição. Trata-se da utilização dos resultados para a elaboração dos planos de ação para o desenvolvimento da escola. É, portanto, na mobilização dos resultados que reside a utilidade da autoavaliação.

Um plano de desenvolvimento da escola é um documento que contém as intenções do coletivo escolar, refletindo a visão de futuro e desenvolvimento necessário à escola. Identifica as prioridades de ação, estabelece as metas e os modos para sua concretização. Bolívar (2003) argumenta que a melhoria da instituição escolar precisa incidir em toda a escola, com uma interseção em três grandes níveis: desenvolvimento da escola enquanto organização, desenvolvimento dos professores e desenvolvimento do currículo. O desenvolvimento do currículo e da organização escolar constitui um campo indissociável.

O desenvolvimento profissional é concebido como um processo contínuo de aprendizagem, que provoca mudanças na aç̧ão profissional do professor, através da forma como atribuem sentido às suas experiências e como estas influenciam as suas práticas diárias, mas, por sua vez, na medida em que o desenvolvimento pessoal e profissional está condicionado pelo contexto da escola enquanto local de trabalho e relação, a formação orienta-se para a consecução de uma estreita articulação entre as práticas formativas e os 
contextos de trabalho, optimizando a dimensão educativa dos processos de trabalho, mediante uma aprendizagem reflexiva e colegial. (BOLÍVAR, 2003, p.68).

Na acepção do autor o desenvolvimento profissional e o desenvolvimento institucional das escolas devem caminhar lado a lado, pois um não existe sem o outro. A possibilidade de desenvolvimento institucional está ligada à capacidade interna de mudança, que é diferente para cada escola, considerando-se a sua história de vida, sua identidade e singularidade, e está condicionada à política educacional e ao contexto social no qual ela se insere. O desenvolvimento institucional é entendido "como as mudanças nas escolas enquanto instituições que desenvolvem as suas capacidades e actuações com vista a uma melhoria permanente”. (FULLAN, 1992, apud BOLÍVAR, 2003, p.75).

O plano de desenvolvimento da escola enquanto instituição deve ser compreendido como o conjunto de ações necessárias para planejar e gerir o crescimento da escola, a sua melhoria contínua, o que pressupõe o fortalecimento da capacidade institucional nos processos internos de trabalho da escola e de decisão sobre as mudanças a serem implementadas.

A elaboração de um plano de desenvolvimento institucional pode orientar-se pelos seguintes questionamentos: Quais mudanças necessitamos fazer na escola? Como essas mudanças podem ser geridas ao longo do tempo? Como podemos conhecer os efeitos ou impactos das medidas adotadas?

De acordo com Alaíz, Góis e Gonçalvez (2003), a elaboração e o desenvolvimento do plano de desenvolvimento institucional envolvem quatro etapas: autoavaliação ou auditoria, planejamento, implementação e avaliação. A primeira etapa constitui-se da análise dos resultados da autoavaliação, identificando os pontos fortes e fracos da escola.
Na segunda, é feita a seleção das prioridades de ação da escola, transformando-as em metas específicas, definindo-se as estratégias e critérios para alcançá-las. A implementação do plano de desenvolvimento constitui a terceira etapa; nela se deve assegurar que o plano é seguido e que as ações previstas estão sendo desenvolvidas. Na quarta etapa avalia-se o sucesso das medidas implementadas e recomendações são propostas para alterações no plano ou para a construção de um novo projeto. Ressalta-se que a avaliação deve ocorrer ao longo do processo de desenvolvimento do plano, numa perspectiva proativa, formativa e reflexiva, possibilitando a introdução dos ajustes necessários durante o seu período de realização.

Em síntese, pode-se apontar que na elaboração do plano de desenvolvimento institucional da escola é necessário contemplar os seguintes procedimentos:

- respeito pelo contexto social, considerando as orientações da política educacional, o projeto pedagógico da escola, as características da comunidade escolar e os recursos disponíveis e necessários;

- consulta e decisão acerca das prioridades, elaborando o plano de forma coletiva, democrática e negociada;

- redação e divulgação do plano, esclarecendo a articulação com os objetivos e fins da escola, justificando a seleção das prioridades, a metodologia ou os recursos envolvidos.

O plano de desenvolvimento institucional, no entanto, não é um fi m em si mesmo; ele é um documento operacional, orientador da ação da escola no seu processo de melhoria. No entanto, a sua elaboração constitui, também, uma oportunidade para a escola e os seus profisionais se desenvolverem, porque: 
- está centrado nos objetivos da escola, especial mente nos processos de ensino e de aprendizagem;

- possibilita uma abordagem integrada de todas as dimensões da escola: o currículo, aprendizagem; a avaliação, o ensino, a gestão e organização, o contexto interno, o contexto externo, os resultados das aprendizagens e da avaliação externa da escola;

- proporciona uma visão de futuro, de longo prazo, da escola na qual os objetivos específicos de curto prazo se enquadram, representando as prioridades do plano de desenvolvimento institucional.

- auxilia na superação da ansiedade dos professores que assim podem controlar melhor a mudança em vez de serem por ela controlados.

- permite maior valorização e reconhecimento do trabalho docente e do desempenho dos professores na promoção da mudança.

- melhora a qualidade da instituição e dos que nela trabalham, porque as reflexões, discussões e decisões coletivas por um lado, ajudam a escola a trabalhar mais eficazmente e, por outro, ajudam os professores a adquirirem saberes e competências como parte do seu desenvolvimento profissional.

- fortalece as relações interpessoais na escola, em especial as da equipe gestora com os professores.

- melhora substancialmente a qualidade do processo educativo e da gestão escolar.

Concluindo, o plano de desenvolvimento institucional é um documento estratégico da escola, pois lhe permite olhar cri- ticamente sobre si mesma, ou seja, sobre a concretização dos seus objetivos principais e dos fins educacionais relacionados com o ensino e a aprendizagem. E, enquanto documento contextualizado deixa que a instituição escolar interprete as dinâmicas internas e o integre na sua vida e cultura.

\section{Considerações finais}

As reflexões teóricas apresentadas neste artigo tiveram como questão central a avaliação da escola e o desenvolvimento institucional, ou seja, a relação entre avaliação na/da escola e a qualidade educativa. Objetivou-se elaborar teoricamente questões sobre a avaliação institucional da escola básica, com ênfase na autoavaliação da escola.

Refletiu-se sobre avaliação educacional na contemporaneidade, situando o debate científico sobre seus objetos de análise e posturas teórico-metodológicas.

Acredita-se que o estudo é fundamental para que, por um lado, se perceba a importância da avaliação educacional para a concretização dos fins educacionais e da escola; e, por outro, se sensibilize para o reconhecimento da interdependência dos múltiplos objetos de análise da avaliação educacional e dos seus níveis de estrutura - micro, meso, macro e megassociológicos -, para a efetivação de um processo avaliativo na escola.

A importância da compreensão dos profissionais da escola de que um processo de avaliação desenvolvido numa postura crítica é essencial para captar o movimento institucional da escola e contribuir para o seu desenvolvimento institucional ficou evidenciada nos diálogos com os autores escolhidos e com as reflexões teóricas desencadeadas. 
A análise das características e abordagens teórico-metodológicas do processo de autoavaliação institucional evidencia que a escola que passa por um processo avaliativo numa postura crítica descobre sua identidade e acompanha a sua dinâmica institucional.

Espera-se que a revisão bibliográfica realizada aponte novos rumos tanto para o desenvolvimento de novas pesquisas como para a realização da avaliação das escolas, particularmente para a autoavaliação institucional, pois se criada e desenvolvida com os sujeitos da escola, ela será possibilitadora do seu autoconhecimento e de ações voltadas ao desenvolvimento institucional, alinhavando sentidos e produzindo significados, tanto aos processos educativos como à comunidade escolar.

\section{REFERÊNCIAS}

AFONSO, A. Avaliar a escola e a gestão escolar: elementos para uma reflexão crítica. In: ESTEBAN, M. T. (Org.). Escola, currículo e avaliação. São Paulo: Cortez, 2003.

ALAIZ, V.; GÓIS, E. GONÇALVEZ, Conceição. Auto-avaliação de escolas: pensar e praticar. Porto: Edições Asa, 2003.

BOLÍVAR, A. Como melhorar as escolas: estratégias e dinâmicas de melhoria das práticas educativas. Porto: Edições Asa, 2003.

BONNIOL, J, J.; VIAL, M. Modelos de avaliação: textos fundamentais. Porto Alegre: Artmed Editora, 2001.

CASALI, A. Fundamentos para uma avaliação educativa. In: CAPPELLETTI, I. F. Avaliação da aprendizagem: discussão de caminhos. São Paulo: Editora Articulação Universidade/Escola, 2007.
CASTORIADIS, C. A instituição imaginária da sociedade. Rio de Janeiro: Paz e Terra, 1975.

FERNANDES, M. E. A. Avaliação institucional da escola e do sistema educacional: base teórica e con do projeto. Fortaleza: Edições Demócrito Rocha, 2002.

FIGARI, G. Avaliar: que referencial? Porto: Porto Editora, 1996.

GUERRA, M. A. S. Tornar visível o quotidiano: teoria e prática de avaliação qualitativa das escolas. Porto: Edições Asa, 2003.

LDB 9394/96 - Lei de Diretrizes e Bases da Educação Nacional. Texto na íntegra. Lei de 20 de dezembro de 1996. Editora e Gráfica Universitária - Unioste.

NÓVOA, A. (Coord.). As organizações escolares em análise. Lisboa: Publicações Dom Quixote, 1995.

ROCHA, A. P. Avaliação de escolas. Lisboa: Editora Asa, 1999.

Enviado em: 12/10/2011

Aceito em: 03/03/2011 